\title{
NUMERICAL MODELLING OF THE DYNAMIC RESPONSE OF LIQUEFIABLE DEPOSITS IN THE PRESENCE OF SMALL SCALE BUILDINGS
}

\author{
Jovana Borozan ${ }^{1}$, Pedro Alves $\operatorname{Costa}^{1}$, Xavier Romão ${ }^{1}$ Julieth Quintero $^{1}$, António \\ Viana da Fonseca \\ ${ }^{1}$ Construct-FEUP, University of Porto \\ Rua Dr. Roberto Frias, 4200-465 Porto, Portugal \\ e-mail: \{ up201607756, pacosta, xnr, julieth, viana\}@ fe.up.pt
}

Keywords: liquefaction, building settlement, numerical modelling.

\begin{abstract}
The impact of liquefaction in building performance during earthquakes is an aspect that has been recently receiving more attention by the technical and scientific communities, in an attempt to reduce the vulnerability of structures located in loose sandy saturated deposits. Currently, the design of buildings in liquefiable layers is performed based on empirical rules, where the liquefaction potential and the ground settlements are usually assessed free-field conditions, i.e., neglecting the presence of the surface structures. Even in the probabilistic approaches that tend to incorporate Earthquake Liquefaction Induced Damages (ELID) from some case-histories that include buildings at the surface, have never incorporated foundations characteristics and loading conditions. However, recent advances in numerical modelling allow performing a more rigorous assessment of the effects induced by liquefaction, namely the settlements that are expected to occur in the spread footings of structures, one of the most common foundation system implemented in small-to-mid-rise constructions in Europe. Therefore, the present paper focuses research on the assessment of the settlements due to earthquake-induced liquefaction that is being conducted within the European Project LIQUEFACT.
\end{abstract}




\section{INTRODUCTION}

Recent earthquakes have led to the development of large settlements and tilting of shallow foundations on saturated sandy/silty soils as a consequence of liquefaction or softening of the foundation soil. The earthquake loading induces an almost undrained response of the soil, giving rise to the accumulation of water excess pore pressure in the soil which results in a significant reduction of the effective stresses. As a consequence, a degradation of the soil's stiffness and shear strength occurs and, if the latter reduces to an amount insufficient to support the weight of the structure, bearing capacity failure is prone to occur, as depicted in Figure 1a. However, even if the bearing capacity failure does not occurs, the reduction of the soil stiffness can lead to very large foundation settlements that can also compromise the safety of the structures (see Figure 1b).
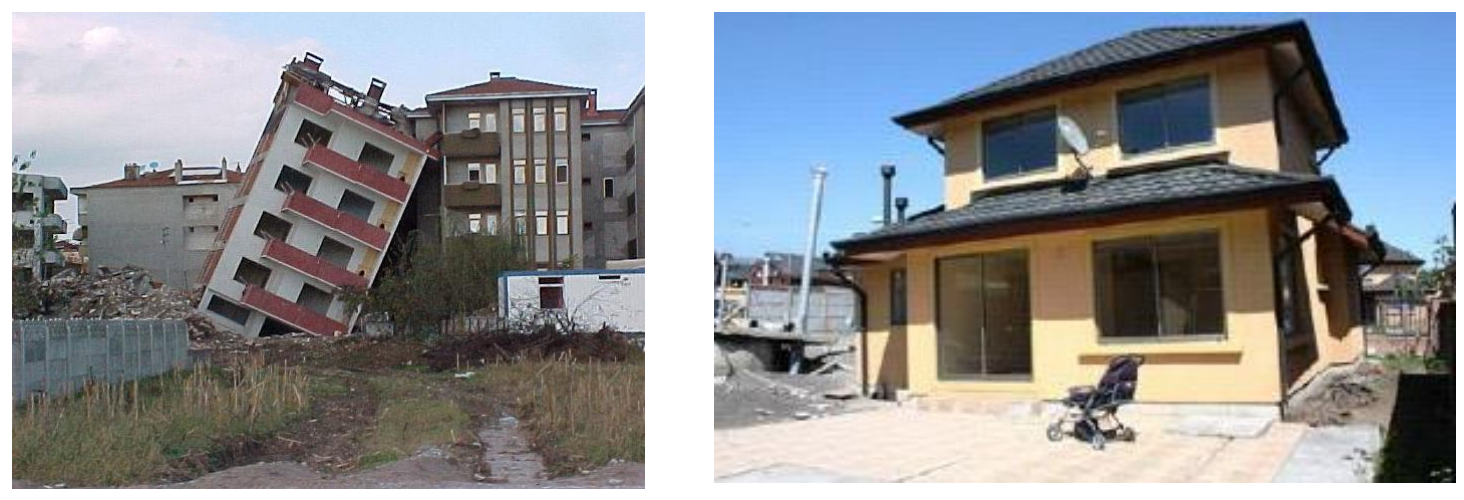

Figure 1 - Damage in structures due to soil liquefaction: a) bearing capacity failure; b) differential settlement.

The problem under analysis is well known by the technical and scientific communities, and has been studied over the past 40 years. Despite recognizing the relevance of this issue, the estimation of liquefaction-induced settlement continues to be heavily based on empirical rules developed to estimate post-liquefaction consolidation settlements in free-field [1,2].

In such simplified approaches, two main parameters are usually considered to be significantly relevant: i) the thickness of the liquefiable layer; ii) the width of the foundation/building. Since simplified approaches are only based on volumetric strain-induced settlements, it is easily seen that the thickness of liquefiable layer should be assumed to be directly proportional to the value of those settlements. For foundations whose width is much larger than the thickness of the liquefiable layer, the presence of the structure has an almost negligible effect on liquefaction-induced settlements, as depicted in Figure 2 [3].

However, these correlations are still not able to justify the very large building settlements and tiltings that have been found at many liquefied sites after the 1999 Adapazari earthquake [4-6]. Larger settlements were observed for taller and heavier buildings. Tilting was noticed for buildings with narrow foundations due to the high contact pressure applied over a small area which led to greater eccentric loading. It has been found that deformations were generally larger for buildings with higher aspect ratio (height over width). 


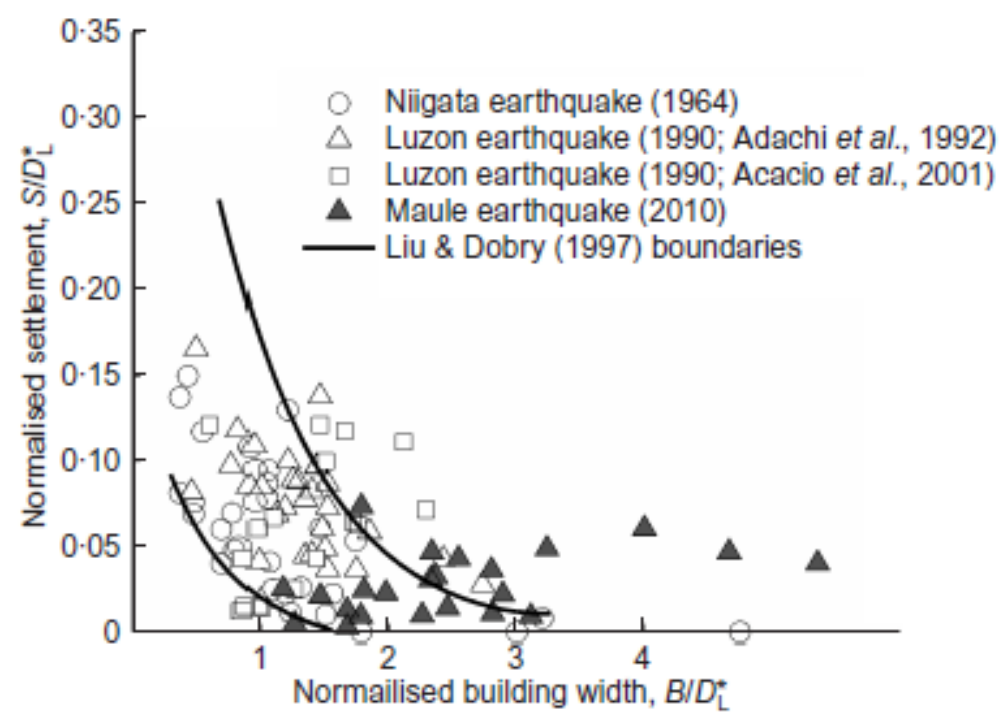

Figure 2 - Normalized foundation settlement vs. normalized foundation width [3]

The experimental evidence of the damage induced in several buildings allowed to conclude that beside volumetric-induced settlement mechanisms, which are prevalent in free-filed conditions, the development of shear-induced settlements is one of the pivotal mechanisms driving the deformation of the liquefied soil, especially in the presence of structures near the ground surface. This which can be associated to the systematic observation of significant values of lateral spreading in ELID documented events, but has not been specifically addressed as an increase important factor in the aggravation of these buildings collapse. As already mentioned, the degradation of the soil shear stiffness and the loss of strength due to pore pressure generation reduces the soil bearing capacity [2]. Consequently, stresses induced below the structure might exceed the soil bearing capacity and result in disastrous deformations such as punching settlements and tilting. Furthermore, the inertial building loading induced by an earthquake might additionally contribute to ratcheting of buildings into the ground. These shear deformations are especially relevant during earthquake shaking since volumetric deformation is not allowed due to undrained conditions at this stage.

The complexity of this soil-structure interaction process is not compatible with simple analytical formulations and demands a robust numerical modelling approach in order to identify some of the key factors of the problem. As a matter of fact, the experimental evidence and observation of damage induced in buildings due to liquefaction should be complemented by numerical modelling that can help achieving a deeper understanding of the problem.

In the present paper, the problem of induced building settlement due to liquefaction is addressed from the numerical point of view. A reference case scenario is constructed in PLAXIS ${ }^{\circledR}$ and a parametric study is then developed in an attempt to understand the effect of the presence of the structure on the settlements occurring during and after an earthquake in scenarios where liquefaction can occur. Performed numerical analyses allow for derivation of certain conclusions, which might be useful for the further research and assessment of numerical modelling of liquefaction effects on built structures 


\section{NUMERICAL APPROACH AND CONSTITUTIVE MODEL ADOPTED}

As previously mentioned, the numerical model was developed in the commercial code PLAXIS. This software has adequate features to deal with complex non-linear dynamic models. The UBC3D-PLM model [7] was selected to simulate the constitutive behavior of the soil. The UBC3D-PLM soil constitutive model is a user-defined model implemented in PLAXIS, which allows for the proper modelling of the seismic liquefaction behavior of sands and silty clays. It is a non-linear, elasto-plastic, effectivestress-based model capable of capturing the evolution of excess pore pressures under undrained cyclic analysis. A detailed description of the constitutive model beyond the scope of the present study and readers are referred to [8,9], among others, for details about the model characteristics. The UBC3D-PLM model is able to simulate the main features of liquefaction without an excessive level of complexity. The model input involves 13 parameters, but several of them have a physical meaning and can be derived from conventional laboratory tests or by empirical correlations with SPT. Nevertheless, others need to be assessed by curve fitting. Table 1 gives the list of input parameters.

Table 1. Input parameters of UBC3D-PML model

\begin{tabular}{|c|c|l|l|}
\hline Parameter & Unit & \multicolumn{1}{|c|}{ Definition } & \multicolumn{1}{|c|}{$\begin{array}{l}\text { Default } \\
\text { Value }\end{array}$} \\
\hline$\varphi p$ & $(\underline{\text { o }})$ & Constant volume friction angle & - \\
\hline$\varphi \mathrm{cv}$ & $(\underline{\mathrm{o}})$ & Peak friction angle & - \\
\hline $\mathrm{c}$ & $\mathrm{kPa}$ & Cohesion & 0 \\
\hline $\mathrm{K}_{\mathrm{B}}^{\mathrm{e}}$ & - & Elastic Shear Modulus & - \\
\hline $\mathrm{K}_{\mathrm{G}}^{\mathrm{e}}$ & - & Elastic Bulk Modulus & - \\
\hline $\mathrm{k}_{\mathrm{G}}^{\mathrm{P}}$ & - & Elastic Plastic Modulus & - \\
\hline $\mathrm{me}$ & - & Elastic bulk modulus exponent & 0.5 \\
\hline $\mathrm{ne}$ & - & Elastic shear moduli exponent & 0.5 \\
\hline $\mathrm{np}$ & - & Plastic shear moduli exponent & 0.4 \\
\hline $\mathrm{Rf}$ & - & Failure ratio & 0.9 \\
\hline$\sigma \mathrm{t}$ & $\mathrm{kPa}$ & Tension cut-off & 0 \\
\hline fac $_{\mathrm{hard}}$ & - & Densification factor & 1 \\
\hline$\left(\mathrm{N}_{1}\right)_{60}$ & - & Corrected SPT value & - \\
\hline fac $_{\text {post }}$ & - & Post-liquefaction factor & $0.2-1$ \\
\hline $\mathrm{P}_{\mathrm{A}}$ & $\mathrm{kPa}$ & Atmospheric pressure & 100 \\
\hline
\end{tabular}

In the numerical analyses that were carried out, tied-degrees of freedom were adopted to simulate the infinite development of the domain along the horizontal direction during dynamic excitation. For the scope of this study, simulated ground motion records matching the Portuguese version of the Eurocode 8 response spectrum for the Algarve region and type 2 seismic action were considered. Since the input ground motion is imposed at the rock-base of the model in PLAXIS, the response spectrum for type A soil conditions was considered to define the ground motions. Figure 3 shows the acceleration time history of the input ground motion considered. 


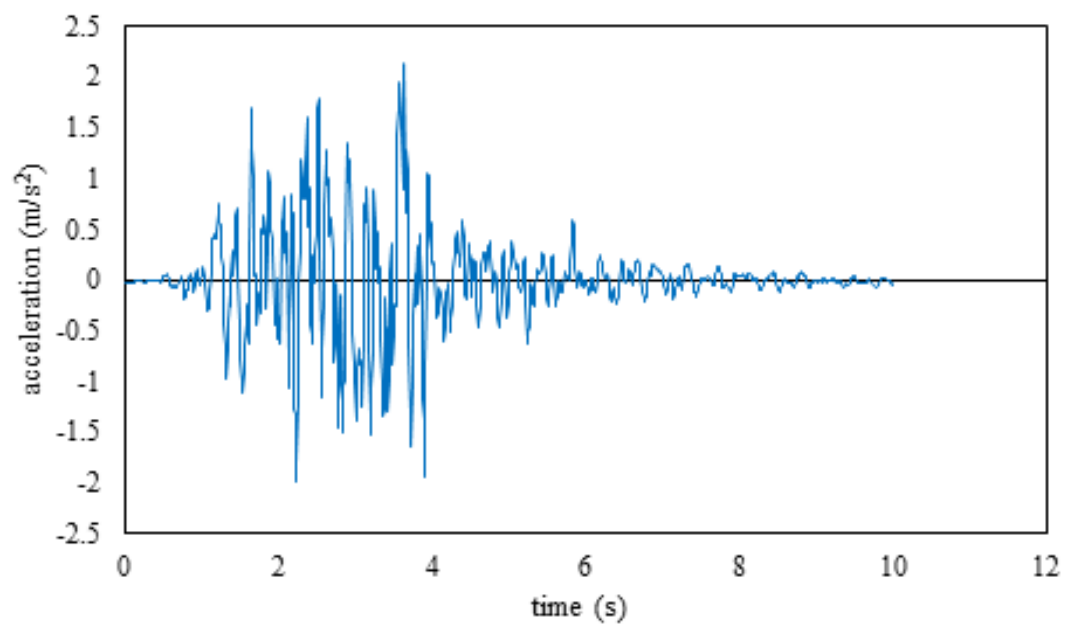

Figure3. Ground motion corresponding to type 2 seismic action

\section{CASE STUDY}

\subsection{General description}

The considered soil profile has three distinguishable layers overlying a thin layer of rock formation as presented in Figure 4. The surface layer, with a total height of three meters, consists mostly of silty sands and clayey silts. The layer below (the second layer) has five meters of loose sand prone to liquefaction and is overlying a four-meterthick third layer of dense sand. The water table is set at the boundary between the first and the second layers. The horizontal dimension of the soil model is 100 meters. The standard penetration resistance (NSPT) values assumed for these layers are 8, 6 and 25 for the first, second and third layers, respectively. The lowest value is assigned to the loose sand layer in order to guarantee its ability to liquefy in the analyses. Table 2 summarizes the parameters of the UBC3D-PLM model adopted for this layer (layer 2) that is susceptible to develop liquefaction.

Table 2. Values of the UBC3D-PLM constitutive soil model parameters for the layer susceptible to liquefaction

\begin{tabular}{|c|c|}
\hline Parameter & Layer 2 \\
\hline$\Phi p\left(^{\circ}\right)$ & 30.34 \\
\hline$\Phi c v ~\left({ }^{\circ}\right)$ & 29.64 \\
\hline $\mathrm{c}(\mathrm{kPa})$ & 0 \\
\hline $\mathrm{K}_{\mathrm{B}}^{\mathrm{e}}$ & 579.37 \\
\hline $\mathrm{K}_{\mathrm{G}}^{\mathrm{e}}$ & 827.67 \\
\hline $\mathrm{k}_{\mathrm{G}}^{\mathrm{P}}$ & 219.5 \\
\hline $\mathrm{me}$ & 0.5 \\
\hline $\mathrm{ne}$ & 0.5 \\
\hline $\mathrm{np}$ & 0.4 \\
\hline $\mathrm{Rf}$ & 0.82 \\
\hline$\sigma \mathrm{t}(\mathrm{kPa})$ & 0 \\
\hline $\mathrm{fac}_{\text {hard }}$ & 1 \\
\hline$\left(\mathrm{N}_{1}\right)_{60}$ & 6.94 \\
\hline $\mathrm{fac}_{\text {post }}$ & 1 \\
\hline
\end{tabular}


Figure 4 shows a schematic representation of the model that was considered for the analyses. The structure introduced in the model is a five-story building, with a total height of 15 meters and a width of 10 meters. The basement level is at a depth of 2 meters measured from the ground floor as well as the water table. A simplified modelling approach was adopted for the building. The walls and floors are modeled with plates and the columns are modelled by beam-column elements. Their material properties are represented in Table1.

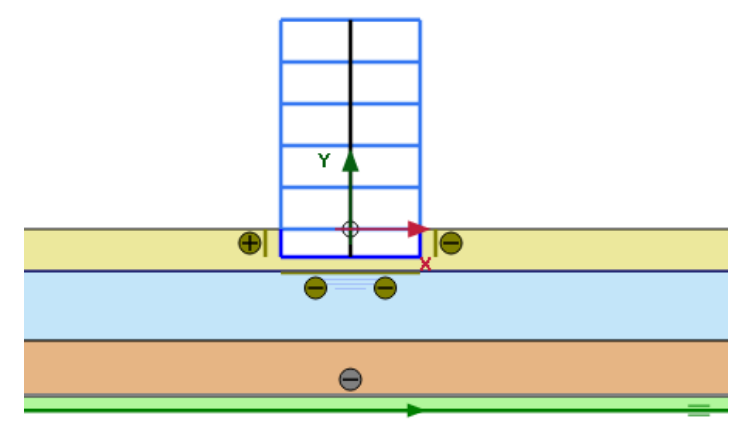

Figure 4 - Representation of the numerical model considered in the analyses

Table1. Material properties of building

\begin{tabular}{|c|c|c|c|}
\hline Parameter & Definition & Upper building part & Basement \\
\hline $\mathbf{E A}(\mathbf{k N} / \mathbf{m})$ & Axial stiffness & $9 \cdot \times 10^{6}$ & $1.2 \cdot \times 10^{7}$ \\
\hline $\mathbf{E I}(\mathbf{k N m} / \mathbf{m})$ & Flexural stiffness & $6.75 \cdot \times 10^{4}$ & $1.6 \cdot \times 10^{5}$ \\
\hline $\mathbf{w}(\mathbf{k N} / \mathbf{m} / \mathbf{m})$ & Weight & 10 & 20 \\
\hline $\mathbf{v}$ & Poisson ratio & 0 & 0 \\
\hline $\boldsymbol{\alpha}$ & \multirow{2}{*}{ Rayleigh damping coefficients } & 0.232 & 0.232 \\
\cline { 3 - 4 } & & $8 \cdot \times 10^{-3}$ & $8 \cdot \times 10^{-3}$ \\
\hline $\boldsymbol{\beta}$
\end{tabular}

\subsection{Analyses and discussion}

The numerical model represented Figure 5 is a reference model used to analyze the response of the structure and of the soil due to the occurrence of liquefaction. The nodes for which the response was analyzed are identified by different letters and are represented as well.

Figure 6 shows the vertical effective stress distribution before the occurrence of the earthquake motion. As expected, there is a non-uniform stress distribution with higher values in layers beneath the building and with a maximum value of $183 \mathrm{kPa}$. During the ground shaking produced by the earthquake, the vertical effective stresses decrease due to the generation of excess pore pressures (Ue) (Figure 7 and Figure 8). However, underneath the building, due to high-induced static shear and vertical effective stresses, the development of excess pore pressure is rather limited. Moreover, this stress state in the area underneath the building might lead to dilative soil behavior during ground shaking, which would explain the larger maximum value of the effective stress at the end of earthquake when compared with the maximum value in the initial state. This also 
means that areas close to the building edges and away from the building generally have a larger liquefaction potential when compared to that of areas underneath the building centerline.

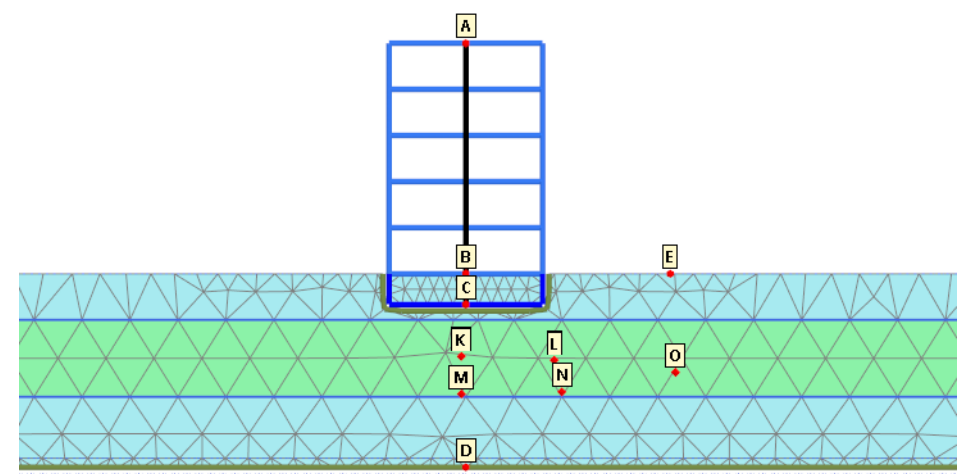

Figure 5. Reference numerical model analyzed in PLAXIS

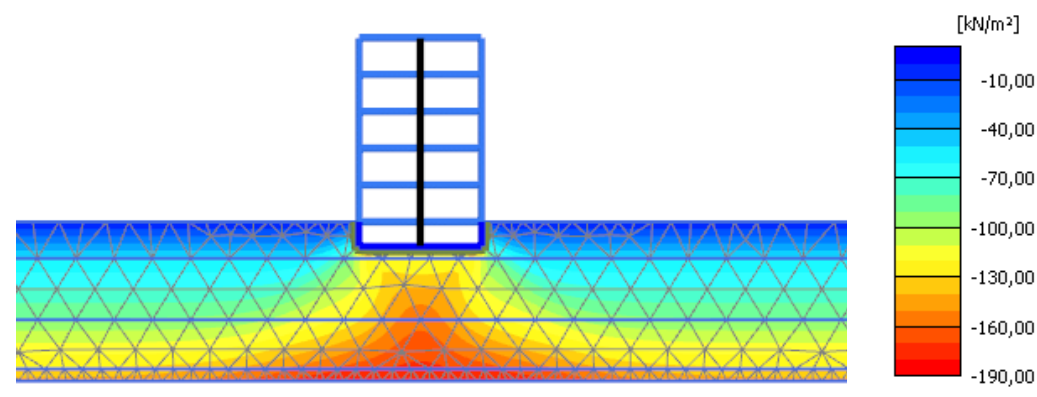

Figure 6. Initial effective vertical stresses ( $\left.\sigma v^{\prime} ’\right)$ - reference model
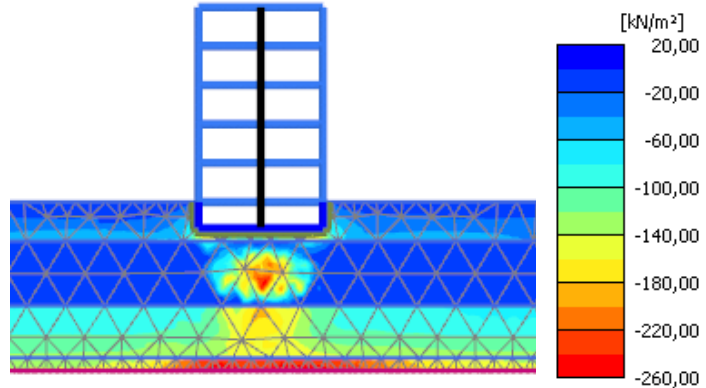

Figure 7. Effective vertical stresses ( $\left.\sigma v^{\prime}\right)$ at the end of earthquake - reference model

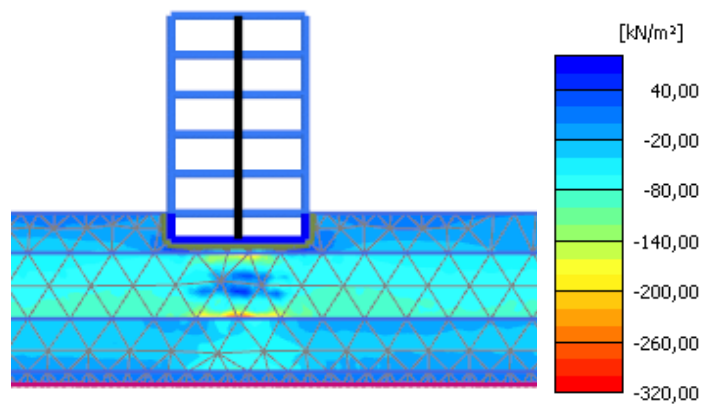

Figure 8. Excess pore water pressures (Ue) at the end of earthquake - reference model

From Figure 9, which represents the evolution of settlements at node $\mathrm{C}$ over time, it can be seen that most of the settlement $(95.7 \%)$ occur during the ground shaking, while only a small part occurs in the post-consolidation stage related to excess pore pressure dissipation. Due to the considerable punching of the building into the soil during the ground shaking, the uplift of the ground surface surrounding the building was observed, as well. As it can be seen, the most significant part of the building settlements occurs due to shear deformation, since undrained conditions were assumed during the earthquake phase. This effect is related to non-uniform stress state installed previously to the occurrence of the earthquake due to the presence of the building, and it will be very dependent on the geometric configuration of the building as well as of the bearing 
pressure applied by the structure to the ground. In the following section, some of these aspects are discussed in more detail.



Figure 9. Development of vertical settlements through time (node C) - reference model

In order to have a better overview of the difference between free-field settlements and building settlements, results from Figure 9 should be compared with the homologous results illustrated in Figure 10, being the last obtained from a model where the building was removed, i.e., for free-field conditions. Due to the imposition of null volumetric strain during earthquake, the ground surface settlement is null at the end of earthquake and only during consolidation phase starts to have some relevance. It is also interesting to see that the settlement during consolidation phase is similar for free-field conditions and for the case where the building presence was considered.

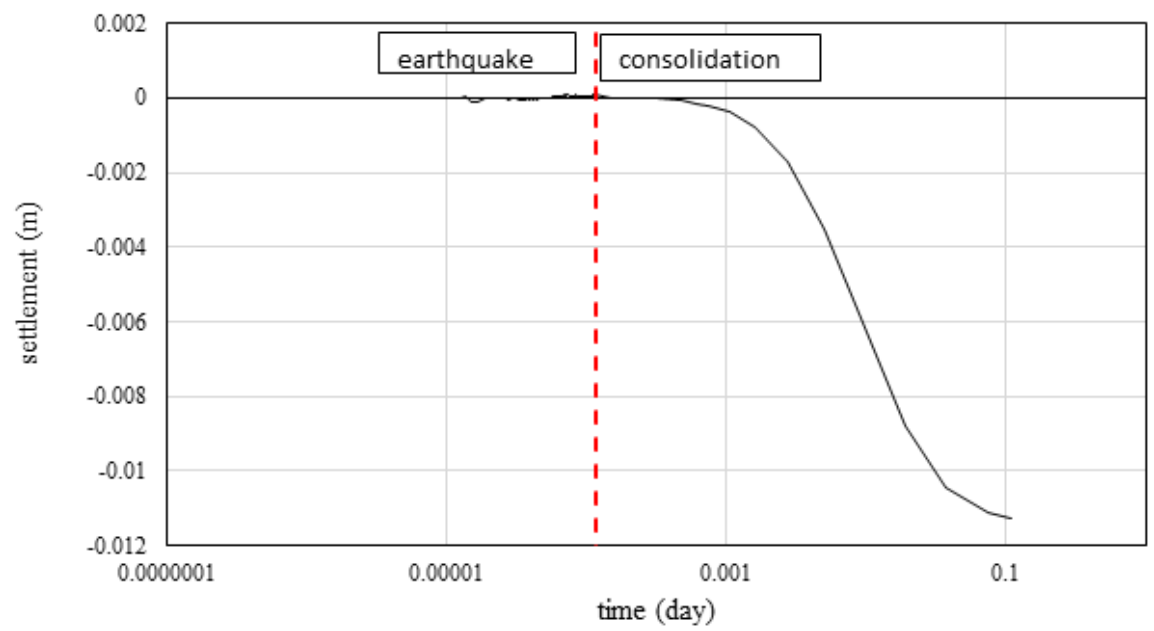

Figure 10. Development of vertical settlement for free-field conditions 


\subsection{Parametric study}

\subsubsection{Model with shorter building}

To better understand the influence of the building height on the value of the settlements induced by seismic excitation, an additional model with a building with only 2 stories was developed. The results obtained are then compared with the reference case that corresponds to the 5-story building. Due to the smaller weight of the 2-story building, the initial effective vertical stresses are lower than for the reference case (Figure 11). After applying the ground motion, a significant drop of effective vertical stress could be observed, especially in layer 2 (Figure 12).

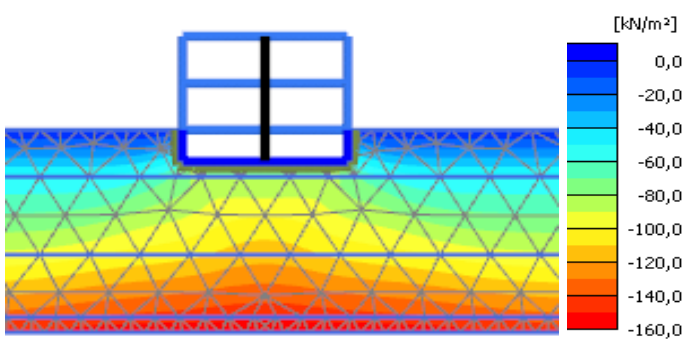

Figure 11. Initial effective vertical stresses ( $\left.\sigma \mathrm{vo}{ }^{\prime}\right)$ 2-story building model

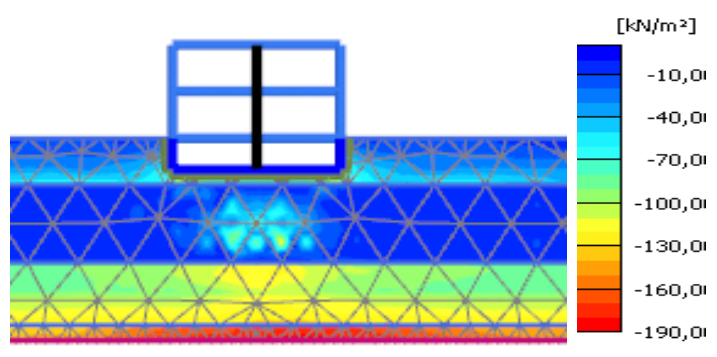

Figure 12. Effective vertical stresses ( $\left.\sigma v^{\prime}\right)$ at the end of earthquake - 2 story building model

Figure 13 represents the evolution of settlements at node $\mathrm{C}$ over time for both the reference model (5-story building) and the new model (2-story building). It can be concluded that in both cases a significant part of the settlement occurs during the ground shaking. However, there is noticeable difference in the magnitude of the settlements for these two models, due to the different building heights. Although not shown in this paper, this effect is mainly due to the lower bearing pressure applied by the shorter building, since the inertial soil-structure interaction does not have a significant relevance for the case study under analysis.

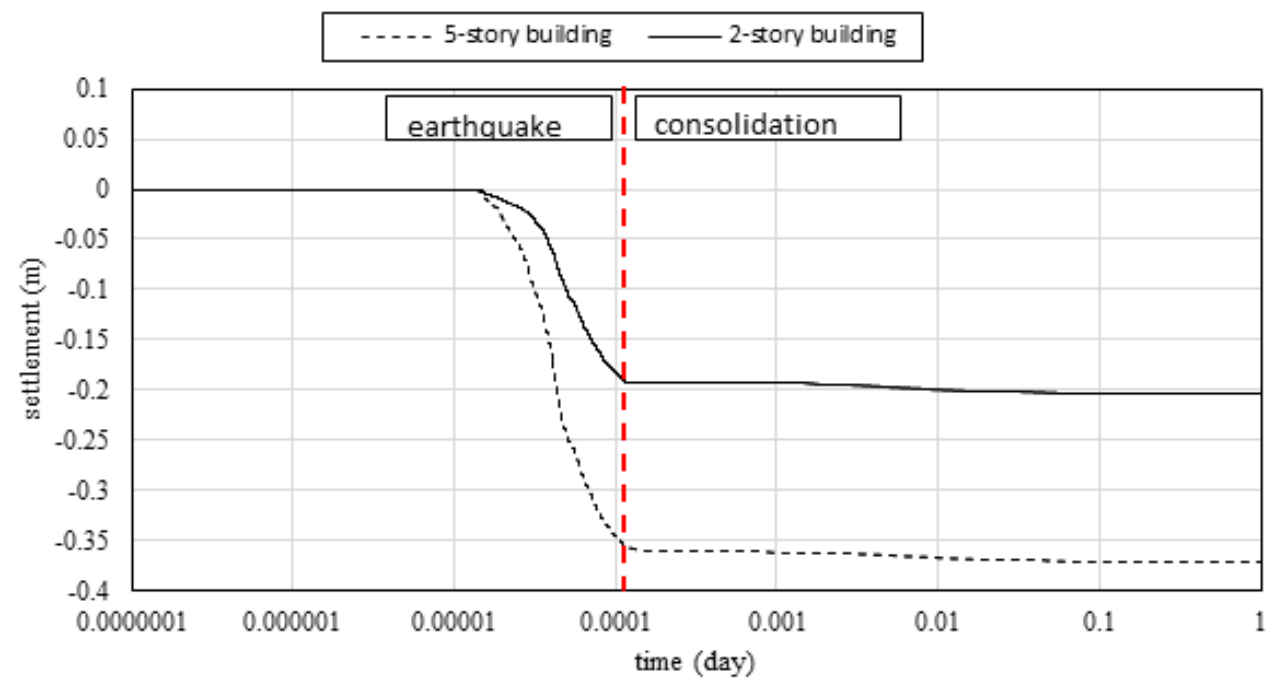

Figure 13. Comparison of liquefaction-induced settlements through time for the two buildings 
It is also quite interesting to see that the magnitude of the settlements during the consolidation phase is similar for both analyses; a larger difference is only seen during the ground shaking phase. This result is compatible with the recent findings of [5], highlighting the role played by the footing bearing pressure in the settlements induced by the earthquake. It should be stressed that the soil bearing capacity, in static conditions, is exactly the same for both cases under analysis.

\subsubsection{Model with wider building}

A model with wider building (20 meters) was also examined to evaluate the influence of the building width on liquefaction-induced settlements. The results were compared with those obtained for the 10-meters wide building corresponding to the reference model.

Extending the width of the building led to a more uniform effective stress state in the ground in the initial condition, as can be seen in Figure 14. Since the considered mat foundation is very stiff, the bearing pressure applied to the ground is similar to the reference case. Nevertheless, the increase of the foundation width implies an increase of the bearing capacity, i.e., the bearing capacity safety factor for static conditions is larger in the present case when compared with the reference scenario.

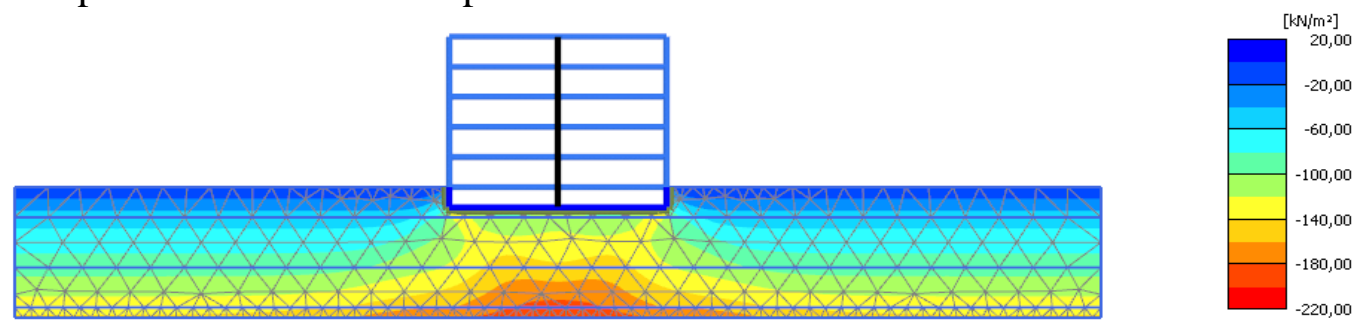

Figure 14. Initial effective vertical stresses ( $\left.\sigma \sigma^{\prime}\right)$ - model with wider building

Figure 15 shows the effective vertical stress distribution at the end of the earthquake while Figure 16 represents the contour map of the excess pore pressure for the same time instant. By comparing those figures with those of the reference scenario, it can be seen that a much more regular pattern is found and it is also noted that the maximum observed excess pore pressure at the bottom of the liquefied layer exhibits a smaller value for the model with a wider building (Figure 16).

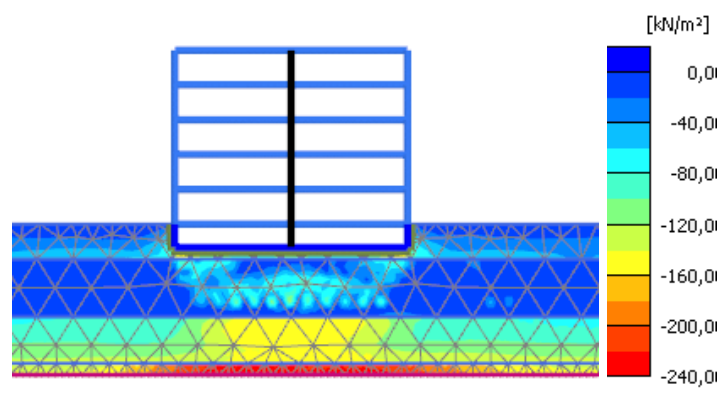

Figure 15. Effective vertical stress ( $\left.\sigma v^{\prime}\right)$ at the end of earthquake - model with wide building

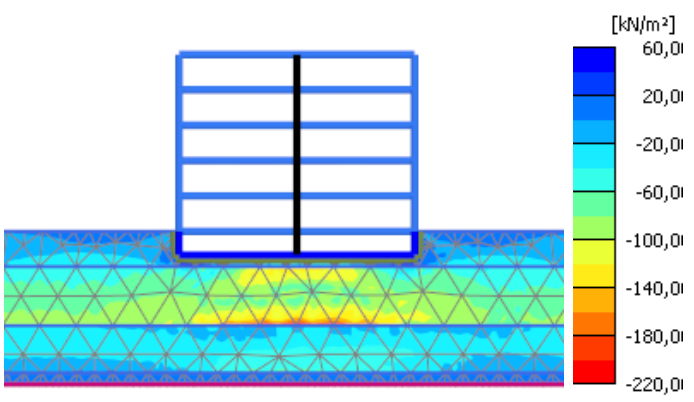

Figure 16. Excess pore water pressure at the end of earthquake -model with wider building

As observed by Liu and Dobry [3] (see Figure 2), for foundations whose width (and thus the depth of influence as well) is larger than the thickness of the liquefiable layer, 
the presence of the building will not influence liquefaction-induced settlements, i.e. the free-field estimate is a reasonable approach in this case. Actually, if the width of the building extends toward infinite, the stress state induced by its presence is uniform and similar to the effect induced by the presence of an additional layer in the upper part of the ground. In that case, and assuming undrained soil behavior during the ground shaking, there is no shear deformation and the settlements due to liquefaction would be due to consolidation effects (Figure 10). Figure 17 compares the settlements that occur over time for the present building and for the reference scenario. As can be seen, much smaller settlements occur when the width of the foundation is doubled. Another relevant aspect to notice is that the settlement during the consolidation phase is almost the same in both situations, being very similar to the settlement observed for a free-field analysis.

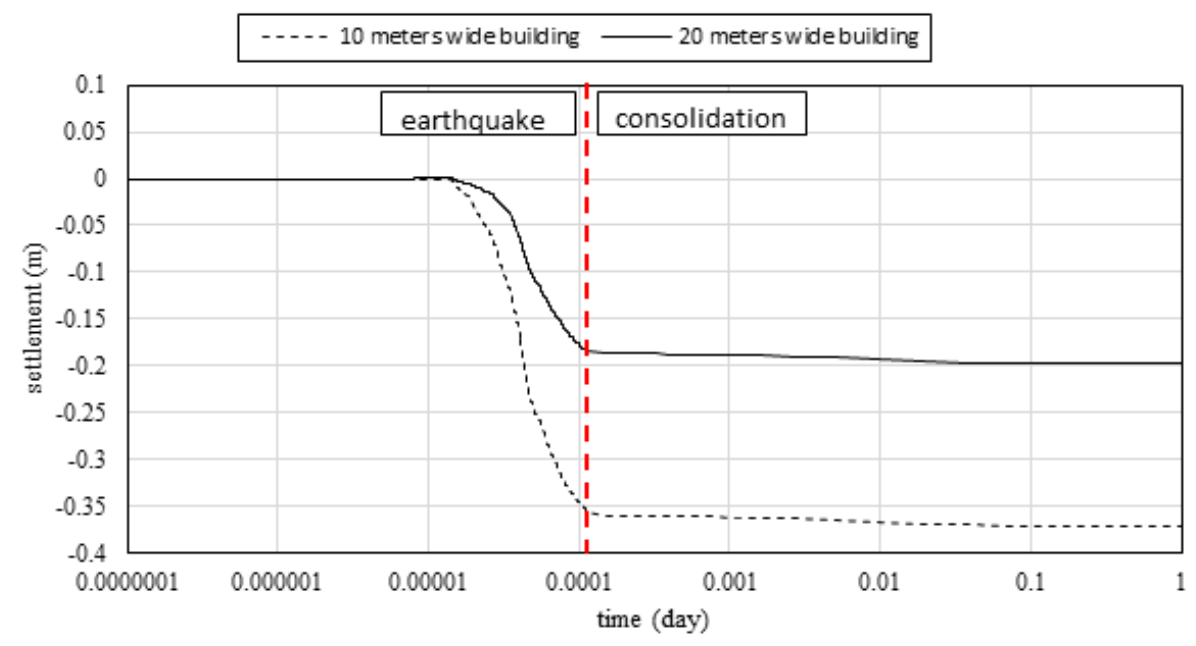

Figure 17. Comparison of liquefaction induced settlements through time

\section{CONCLUSIONS}

In the present paper a simple parametric analysis was done to evaluate the impact of some factors on the settlement of buildings due to earthquake liquefaction effects. From the obtained results, it is seen that the presence of the building leads to large settlements during the earthquake, even if undrained conditions are assumed for the soil behavior. The application of simple procedures based on free-field conditions to estimate building settlements due to liquefaction, which are essentially based on consolidation after the generation of pore pressure during the seismic action, are not suitable. Indeed, during the earthquake the major part of the building settlement is due to the loss of bearing capacity or by soil softening due to a decrease of the mean effective stresses in large zones of the ground beneath the foundations, subjected already to high deviatoric stress levels in service conditions. From the parametric study that was developed, it was clear that building settlements depend not only on the earthquake demand but also on the static safety factor of the foundation. In the present analysis, it was shown that decreasing the building height leads to lower settlements or, in other words, when decreasing the bearing pressure, i.e. increasing the bearing capacity safety factor, a strong reduction of the settlements is observed. In the same way, when increasing the foundation width while maintaining the same bearing pressure of the reference case, a strong reduction of the settlement also occurs. In fact, for the same bearing pressure, the increase of the foundation width corresponds to an increase of the bearing capacity, i.e. of the static safety factor of the foundation. 
In sum, the static safety factor of the foundation appears to be an indicator that should be considered for the development of simplified models to estimate building settlements due to liquefaction, in addition to other indicators such as earthquake properties and soil characteristics and state conditions.

\section{ACKNOWLEDGEMENTS}

This work was financially supported by: Project POCI-01-0145-FEDER-007457 CONSTRUCT - Institute of R\&D in Structures and Construction funded by FEDER funds through COMPETE2020 - Programa Operacional Competitividade e Internacionalização (POCI) - and by national funds through FCT - Fundação para a Ciência e a Tecnologia.

LIQUEFACT project (“Assessment and mitigation of liquefaction potential across Europe: a holistic approach to protect structures / infrastructures for improved resilience to earthquake-induced liquefaction disasters") has received funding from the European Union's Horizon 2020 research and innovation programme under grant agreement No GAP-700748. The support given by Erasmus + grant for mobility traineeship in higher education is highly appreciated by the first author.

\section{REFERENCES}

[1] Tokimatsu, K. and H. Seed, EVALUATION OF SETTLEMENTS IN SANDS DUE TO EARTHQUAKE SHAKING Journal of Geotechnical Engineering, 1987. 113(8): p. 861878.

[2] Karamitros, D.K., G.D. Bouckovalas, Y.K. Chaloulos and K.I. Andrianopoulos, Numerical analysis of liquefaction-induced bearing capacity degradation of shallow foundations on a two-layered soil profile. Soil Dynamics and Earthquake Engineering, 2013. 44: p. 90-101.

[3] Liu, L. and R. Dobry, Seismic Response of Shallow Foundation on Liquefiable Sand. Journal of Geotechnical and Geoenvironmental Engineering, 1997. 123(6): p. 557-567.

[4] SANCIO, R., J. BRAY, T. DURGUNOGLU and A. ONALP, PERFORMANCE OF BUILDINGS OVER LIQUEFIABLE GROUND IN ADAPAZARI, TURKEY, in 13th World Conference on Earthquake Engineering 2004: Vancouver, B.C., Canada.

[5] BERTALOT, D., A.J. BRENNAN and F.A. VILLALOBOS, Influence of bearing pressure on liquefaction-induced settlement of shallow foundations. Géotechnique, 2013. 63(5): p. 391-399.

[6] Bray, J.D. and S. Dashti, Liquefaction-induced building movements. Bulletin of Earthquake Engineering, 2014. 12(3): p. 1129-1156.

[7] Beaty, M. and P.M. Byrne, An Effective Stress Model for Predicting Liquefaction Behaviour of Sand, in Geotechnical Earthquake Engineering and Soil Dynamics III, ASCE Geotechnical Special Publication No. 75, P. Dakoulas, M. Yegian, and R. Holtz, Editors. 1998. p. 7765-777.

[8] Galavi, V., A. Petalas and R.B.J. Brinkgreve, Finite Element Modelling of Seismic Liquefaction in Soils. Geotechnical Engineering Journal of the SEAGS \& AGSSEA, 2013. 44(3): p. 5564.

[9] Petalas, A., Validation and Verification of a Practical Constitutive Model for Soil Liquefaction in PLAXIS, in 2012, TU Delft: Delft, The Netherlands. 